dation filling that roomy cavity in the petrous bone. (See autopsy). Purulent discharge.

Three days' treatment in hospital ; violent head. ache, for which patient took large dose of morphia; patient died May 5, after gradually increasing coma.

Autopsy.-In brief, cochlea internal meatus and the nerves terminating within were intact; the facial in its course between the two bends of the fallopian canal also offers nothing noteworthy; below the second bend the wall toward the drum cavity is destroyed, and the nerve is separated from the plug of exudation filling the above mentioned cavity, only by a thin mucous membrane.

The first case is interesting in regard to the location of the polypoid growth, in the posterior portion of the tympanic cavity, and that pressure on the mass and upon the region in front of the ear, causing severe vertigo; in connection with the observations of Politzer on the occurrence of openings in, or thinning of the bony wall of the facial canal; in relation, also, to a previous and evidently severe inflammatory process within the tympanic cavity, which may in its results have paved the way for the peculiar symptoms occurring with the latter disease; and also of interest as concerns the degree of recovery attained after a facial paralysis existing for a long period, as shown by the results of the treatment above given by Drs. Blake and Webber. Occurrences of the nature in the first and second cases render intelligible the well established fact that paralysis occurring in the brain, with purulent otites medea, may stop ${ }^{\prime}$ as soon as the cause maintaining the paralysis ceases. Absorption of the masses of exudation compressing the nerve is certainly not impossible, if proper and careful treatment is followed. Green ${ }^{2}$ reports a case (death ensued from meningitis), no cerebral abscess present, in which the fallopian canal was likewise open towards the drum cavity, so that the facial nerve appeared covered directly with the swollen mucous membrane.

\section{THE SCIENTIFIC DUTIES OF MEMBERS OF MEDICAL SOCIETIES.}

BY H. B. HEMENWAY, M.D., KALAMAZOO, MICH.

[Read before the Kalamazoo District Medical and Surgical Association, Sept. 23, 1883.]

The physician is a scientist and an artist. In but few individuals do we find the two combined in equal proportions. In some the artistic principles are predominant. Others have come to devote nearly their whole attention to the science of physic. The latter form by far the less numerous class. The art and the science are therefore distinct, but they are also intimately connected. The former, as old as the human race probably, is very successful when founded upon scientific principles; while the other had its origin in the art.

We have just said that the art is only successful when it is founded upon scientific principles, and yet it is a well-known fact that the most learned are often very poor practitioners. On the other hand a very ignorant man may be eminentiy successful, especially in some particular line of cases. 'This is no refutation, however, of the statement made. Our best instructors in music are very often very ordinary players. They understand what makes sound, music, and discord. They may be thoroughly acquainted with the laws of harmony and with the method of instrumental manufacture in all its minutiæ, but they have not such command of their muscles as to do as well as they know, and in execution frequently the scholar excels the master. The same is true, though probably in a less degree, in our own profession. The empiric is not conversant with the truths upon which his treatment is based. Others have worked out problems to which he remembers the answers. It is a lamentable fact that too often the country physician permits himself to drop into this sort of quackery. He may have had the best of college education. $\mathrm{He}$ may have been under the guidance of the most learned of our profession. As he left his alma mater he may have done so under the most auspicious circumstances. When he becomes established in practice, however, he has occasion, for example, to dispense his own medicines. For a cathartic he gives the compound cathartic pills of the pharmacopœia. He finds them satisfactory, and buys them by the wholesale rather than make them himself. In the course of time he forgets the exact composition of the pills, but he gives them right along, thinking not so much of the special bearing of each drug upon the case, as that he wants to get a movement of the bowels, and they do the work. He desires something to relieve pain. P. D. \& Co.'s chloranodyne is handed him. He tries it, likes it, and adds it to his list. "Tougaline" is his remedy for rheumatic neuralgia, but in nine cases out of ten, the doctor prescribing it cannot tell its composition. If he is reproached with using these ready-made preparations, he will tell you that he has not time to compound drugs. He has tried the combinations and is satisfied with the results. $\mathrm{He}$ knows about what cases this or that remedy is good for, and where it will do harm. Why not then designate each combination by a special number? What is there out of the way in a local drug firm scattering hand-bills, which tell the people that Dr. ' $\Gamma$ 's No. 29 is a specific for dyspepsia, and No. 45 is highly recommended for " female weakness?" If it is known that Dr. A prescribes "Dyspepsum," why should we object if druggist B recommends "Ingluvin ?" The time is not far in the past when a president of our own State Medical Society was sending to lady patients all through the country two kinds of powder, both bi-carbonate of sodium and chloride of ammonium, I think, but one was colored with cochineal. How much worse is that than if he had put them upon the market labeled "Zoa-phora?"

There is another objection to prescribing ready nuade mixtures. The physician becomes less discriminative in his use of drugs, and is thus led to use more than is necessary. Take the use of Dover's Powders for a "cold." It is by no means impossible that in very many cases the result would be as perfect without the opium, and there would not therefore be the risk of getting the opium habit.

This is not the only danger for the country pracitioner. He finds his time so fully occupied that 
his journals do not get the thorough reading which he desires. His cases are so far apart that he can not so easily study them critically as he could if they were side by side in the wards of a hospital. Often he sees a case so seldom, and so short a time that his history of the disease must be imperfect. For a like reason he is very slow to try a new remedy. His work naturally drops into routine. In this malarious region, for example, in a large majority of cases he will give quinine, even though he might not get clear indications of malarial poisoning. What is the result of this line of work?

Years ago, in the clear air of New England, if a patient was found suffering with pneumonia in its earlier stage, his veins were opened and his chance for recovery was good. With the tide of emigration into this State the disciples of Asculapius came also. Here too pneumonia was found. Of the diagnosis there was no doubt, ergo venesection was practiced, but the more blood was extracted the more surely did the patient die. In the one case there was the sthenic type, and by diminishing the amount of blood pressure, the infiltration of lung tissue was diminished, there was less to be absorbed or to break down, and the patient's chances for recovery were better. In the other instance the system had already been depleted by malaria and exposure. In such a case it were clearly better to do nothing at all than to diminish what little strength the patient had left. As a consequence the regular practitioner, relying more upon his former experience with the disease in question than upon his careful study of the case before him, saw his patients laid away for their final rest, while his neighbor was rich in giving directions to "take a teaspoonful out of each glass alternately an hour apart."

In that humorous historic poem found in "Percy"s Reliques," upon "King John and the Abbot of Canterbury," the Abbot's shepherd cheers his master by the question:

* * * * "Did you never heare yet, That a fool he may learne a wisse man witt?" We are also reminded that Sir Walter Scott once said that if after a half hour's conversation with any man, no matter how ignorant, he found that he had learned nothing, he began to suspect that he himself was the greater fool of the two. As scientists we have no right to cast aside and condemn as valueless any system until we have thoroughly examined it and extracted all that has worth.

$* * * * * * * * * *$

A scientist's duty is not done when he carefully collects the ideas and observations of others. He should endeavor to discover new truths. So one of our duties as medical practitioners is to widen the fouldation upon which others are to build the future. Our common title indicates this, and it is a very objectionable feature of our American educational scheme that the term "doctor" is here so common and so meaningless. Legally, the man who has registered in our own county as having received his degree after studying twelve weeks in a Chicago homœopathic school has just as much right to be called "doctor" or "teacher" as the venerable president of our American Medical Association, or that surgeon from the City of Brotherly Love who has been honored in old Oxford with the degree of D.C.L. The degree M.D. here gives one little, or no idea of the knowledge which the bearer thereof possesses. It tells nothing of his social or moral standard. It behooves us then, as members of this society, so to conduct ourselves as to raise the professional standing in this community.

This is now the only active medical society in this region of country. To this society every honest physician within its bounds should belong. It ought to be a college of teachers who will exert an influence for good over the whole State. Do you ask "How is this to be accomplished?

In the first place, the Association ought to use every means in its power to uphold and enforce all State and local sanitary laws. It is a well-recognized fact, for example, that the recent law regulating practice in this State is a very weak and defective piece of work. It is a law, however, and every member ought to be a committee of one to see that it is not broken. We should be thankful for small favors, and regard this as but an opening wedge.

Secondly. As a society we ought to have a good professional museum and library for reference. If we are going to allow ourselves to depend upon what we have learned in the past with what little we may pick up, we shall not need a society library. But how many of us have such a large supply of medical literature that we could not soon exhaust it in studying any subject?

The social gathering is a highly desirable or important feature of our meetings; but for that alone the majority of us cannot afford to give up all other work. Every person who has a privilege has also a duty. There are some men who are perfectly able to work who allow themselves to live at others' expense. There are also in some societies drones, who come regularly to take all they can get of the fruit of other men's work, but never condescend to collect the golden nectar for the common store. In some medcal societies, too, there are those who come around when it is convenient, discuss in an off-hand manner the subject under consideration, and perhaps they relate the symptoms of some case under their observation. But the duties of the members of this society do not end there. We ought to have not less than one good, thorough, scientific article read at each meeting. Am I wrong in saying that any man or woman who does not present such a paper as often as once in three years, is not worthy of being a member? I think that is not too strong a statement. Nor ought it to be left to the Secretary to find those to write such articles, especially since some refuse to prepare them when requested. It may be objected that the busy practitioner cannot find the time. Read Samuel Smilie's "Self Help," or Dr. John Brown's "Spare Hours." I remember that when I was in college one or two of the professors were frequently absent when their turn came to lecture. They always had this same excuse of professional business. It was a note- 
worthy fact, however, that those who had the largest practice were the most sure to fill their hours.

Would it not elevate the standard of the society to require that every person should read before the Association a paper showing original investigation in some line of professional work before he snould be admitted to membership.

What kind of paper do you want? We want them short and clear. Do not repeat in order to make the article longer. Do not try to cover too large a field. Let the article consist of a general review of the subject, followed by a more minute examination of some particular portion, with personal notes, if possible. A compilation and analysis of the thoughts and observations of others is better than nothing at all; but original investigations are the most needed. Distinguish clearly between fact and theory. Such a paper would not only be profitable to the whole society, but it would benefit its writer far more.

As a society we ought to make some original investigations. Take diphtheria one year and require each member to note down and report every case under his observation, telling age, exposure, both as to time and kind, duration of disease, treatment and result; water used; house clean; condition of cellar? The next year we might take pneumonia In such work it would be better to work with the committee of the American Medical Association in accordance with the report of the JourNaL of August 25.

Our highest duty and privilege is not to deal out. physic, but to preserve the health of the community in which we live. This we must do as public teachers. At the last meeting of the American Medical Association it was recommended that each county society establish a school for nurses. Said school to be conducted as best might stit the circumstances, but probably on the lecture plan. Do we not need such a school here? And would we not be personally benefited?

\section{NOTES ON TRACHEOTOMY, WITH CASES,}

BY. W. H. MYER, M.D., FT. WAYNE, IND.

[Read in the Tri-State Medical Society, September, $188_{3}$.]

"It is not new facts that avail, but the heat to dissolve everybody's facts."--Emerson.

FOREIGN BODIES IN THE AIR PASSAGES.

I will not discuss the nature of the bodies introduced, how introduced, nor the somptoms developed by their presence; but the prognosis, and that only so far as it refers to the effects.

Of the operation itself I have only this to say: It should not exist-at any rate in the professional mind-as a dernier resort, for this would delay the surgical treatment, and the prognosis would be accordingly extremely grave, believing with Trousseau that "there is an imperative duty imposed upon the practitioner of performing tracheotomy as obligatory as tying the carotid artery when that vessel has been

I Troeltsch, Lehrbuch, p. 413, seg.

2 "Cases of Fatal Otorrhoa," Boston Med. and Surg. Jour., Nov 30. wounded, although death quite as often as recovery follows the operation."

I will further urge the propriety of early operation in all cases of tracheal obstruction, whether depending upon the presence of foreign bodies or obstruction from disease, differing, as I am well aware, from Dr. Wiest, who recently published an extremely interesting paper on this subject. In it he enunciates the following propositions:

r. "The presence simply of a foreign body in the larynx, trachea or bronchi does not make bronchotomy necessary."

2. "While a foreign body causes no dangerous symptoms, bronchotomy should not be performed."

These inferences were based upon 937 cases; of these 599 were not operated upon, 76.79 per cent. recovered and 23.20 per cent. died. Bronchotomy was performed in 338 cases; 72.48 per cent. recovered and 27.42 per cent. died, leaving in favor of non-interference $4.3^{I}$ per cent. The fallacy of the argument is apparent when the author attempts to determine in what cases bronchotomy should be performed. This difference furnishes the solution to the results in the tables, and vitiates their value in the light in which the author presented them; for it is evident all the difficult cases would be included in the list operated upon, and the less difficult, where spontaneous expulsion took place and caused but little disturbance, these would be found in the class where nature effected the cure.

These tables establish the following conclusions: :

I. When foreign bodies were easily expelled-for instance seeds-recoveries took place in a larger per cent. than in the cases subjected to bronchotomy.

2. Only those where spontaneous expulsion had not taken place, and the symptoms were urgent-the bad cases - those threatened with asphyxia, inflammation and its products, were subjected to bronchotomy.

"Modern medical literature teems with statistics as to the results of tracheotomies. Their study only establishes the conclusion that the operation must be made with reference to the individual case in question, rather than with regard to the proportionate number of recoveries." The above is the language of one of our most enlightened specialists. While I will not attempt to deny the value of statistics, when properly presented, yet in medicine, we know the plainest rules of philosophical investigation have been disregarded. Things have been associated having no necessary relation, and conclusions have been drawn that had but an indifferent foundation in fact. Statistics imply something more than a process in arithmetic. They should be a profound philosophical analysis of materials carefully collected, with an enlightened confidence in their fitness for the purpose in question.

Without the proper regard for the principles here enunciated, they have been singularly barren of results. When the historian, the chemist and the naturalist require unexceptional authority for the statistical facts, and do not hesitate to subject then to a rigid scrutiny, only then do they become of any value. They must be applied only to incidents and events that have an objective existence, and just so far as 